\title{
Oligometastatic Non-Small Cell Lung Cancer: A Significant Entity outside of Specialized Cancer Centers?
}

\author{
Carsten Nieder ${ }^{a, c}$ Terje Tollåli ${ }^{b}$ Anne Reigstad ${ }^{b}$ Adam Pawinski ${ }^{a}$ \\ Ellinor Haukland ${ }^{\mathrm{a}}$ Astrid Dalhaug ${ }^{\mathrm{a}, \mathrm{c}}$ \\ Departments of a Oncology and Palliative Medicine, and b Pulmonology, Nordland Hospital, Bodø, and \\ ${ }^{c}$ Institute of Clinical Medicine, Faculty of Health Sciences, University of Tromsø, Tromsø, Norway
}

\section{Key Words}

Non-small cell lung cancer · Disease stage · Staging ·

Metastases · Oligometastases

\section{Abstract}

Objective: To report the incidence, patterns of care, and outcomes of oligometastatic non-small cell lung cancer (NSCLC) in a rural practice setting in Norway. Materials and Methods: A retrospective analysis was conducted of all patients with stage IV NSCLC at the initial diagnosis who received active treatment in the central part of Nordland, a rural county in northern Norway, during the period of 2006-2012. We analyzed overall survival and prognostic factors. Results: The initial study population included 113 patients with stage IV disease who received active therapy; of these, 23 (20\%) had oligometastatic spread (a maximum of 3 metastases to 1 organ). The median age was 71 years. Of the 23 patients, 16 (70\%) did not receive radical or at least moderately aggressive local treatment for their thoracic disease. Of the remaining 7 patients, 4 (17.4\%) did not receive systemic therapy. The median actuarial survival was 5.6 months in patients with more advanced metastases and 11.7 months in those

\begin{tabular}{ll}
\hline KARGER & $\begin{array}{l}\text { ( } 2014 \text { S. Karger AG, Basel } \\
\text { 1011-7571/14/0236-0526 } \$ 39.50 / 0 \quad \text { Karger }\end{array}$ \\
E-Mail karger@karger.com & $\begin{array}{l}\text { This is an Open Access article licensed under the terms of the } \\
\text { www.karger.com/mpp }\end{array}$ \\
& $\begin{array}{l}\text { Creative Commons Attribution-NonCommercial 3.0 Un- } \\
\text { ported license (CC BY-NC) (www.karger.com/OA-license), } \\
\text { applicable to the online version of the article only. Distribu- } \\
\text { tion permitted for non-commercial purposes only. }\end{array}$
\end{tabular}

with oligometastases $(p=0.03)$. Significant differences were also seen between the 2 oligometastatic patient groups with and without more intense thoracic treatment (median 19.7 vs. 7.6 months, $p=0.004$ ). Further significant predictors of survival in patients with oligometastases were nodal stage $(p=0.028)$ and weight loss $(p=0.045)$. Trends were seen for T stage $(p=0.058)$ and performance status $(p=0.07)$. Conclusion: Oligometastatic NSCLC was diagnosed in a relevant proportion of patients; therefore, warranting prospective studies are recommended. Such studies are also needed to confirm the treatment-dependent survival differences observed in our patient population.

(c) 2014 S. Karger AG, Basel

\section{Introduction}

Distant metastatic stage IV non-small cell lung cancer (NSCLC) is a common and serious diagnosis, with survival typically limited to months rather than years [1]. However, the patterns of spread and the total tumor burden vary widely [2]. Some patients might initially present with multiple liver, adrenal gland, and bone metastases, 
while others harbor a solitary brain metastasis [3]. It has long been recognized that patients with a solitary brain metastasis and limited thoracic disease might experience favorable long-term survival after effective local therapy [4]. Historically, cohort studies published during the 1980s with treatment dating back to even earlier decades already described the concept of surgical treatment in NSCLC with a solitary brain metastasis, which resulted in variable rates of 5-year survival [5]. Later on, stereotactic radiosurgery was used for some patients with brain metastases, and more recently, the introduction of extracranial stereotactic ablative radiotherapy has enabled us to provide noninvasive highly efficacious local therapy to different sites of oligometastases [6]. The latter paradigm is based on the hypothesis that subgroups of patients with stage IV NSCLC might be candidates for aggressive local treatment based on disease extent and the feasibility of such therapy, and that those with oligometastatic disease might fare better than the majority of patients, i.e. those with widespread distant metastases. The exact definition of oligometastatic NSCLC remains to be agreed upon. It is also not fully understood whether differences in tumor biology, treatment approaches, or both can adequately explain the different course of the disease, or whether local treatment at all sites of disease should be attempted. Most previous studies emanated from large institutions that might or might not see patients who are comparable to real-world NSCLC cohorts, due to referral characteristics [7-9]. Therefore, we evaluated an unselected patient group from a rural area treated with or without local therapies of different efficacy. Based on previous studies, we hypothesized that radical or at least moderately aggressive local treatment of the primary tumor and the involved regional lymphatics ( $\mathrm{T}$ and $\mathrm{N}$ sites) might improve survival.

\section{Subjects and Methods}

Since this is a retrospective quality-of-care analysis, no approval from the Regional Committees for Medical and Health Research Ethics (REK) was necessary. This retrospective study included all patients with stage IV NSCLC who received care at one of Nordland Hospital Trust's (NHT) 3 somatic hospitals in the county of Nordland, northern Norway. The NHT is owned by the Ministry of Health and Care Services and is administered through a regional trust (North Norway Regional Health Authority Trust). It provides specialist health care Services to approximately 112,000 inhabitants, i.e. roughly $50 \%$ of the population of the county (a geographically widespread, largely rural area) including its main city Bodø. The remaining areas of the county (extreme north and south) are served by other hospitals. The NHT is the exclusive on-
Table 1. Baseline patient characteristics ( $n=23$ with oligometastases)

\begin{tabular}{|c|c|}
\hline Parameter & Patients, $\mathrm{n}$ \\
\hline \multicolumn{2}{|l|}{ Gender } \\
\hline Male & 19 \\
\hline Female & 4 \\
\hline \multicolumn{2}{|l|}{ ECOG performance status } \\
\hline 0 & 4 \\
\hline 1 & 10 \\
\hline 2 & 9 \\
\hline \multicolumn{2}{|l|}{ Smoking status } \\
\hline Active & 5 \\
\hline Never & 2 \\
\hline Quit at least 1 year before the diagnosis & 12 \\
\hline Quit less than 1 year before the diagnosis & 4 \\
\hline \multicolumn{2}{|l|}{ Comorbidity } \\
\hline None & 9 \\
\hline 1 & 8 \\
\hline 2 or more & 6 \\
\hline \multicolumn{2}{|l|}{ Weight loss } \\
\hline None & 13 \\
\hline$<5 \%$ & 2 \\
\hline $5-10 \%$ & 6 \\
\hline$>10 \%$ & 1 \\
\hline Unknown & 1 \\
\hline \multicolumn{2}{|l|}{ Histology } \\
\hline Adenocarcinoma & 10 \\
\hline Squamous cell & 6 \\
\hline Large cell & 1 \\
\hline Not specified & 6 \\
\hline \multicolumn{2}{|l|}{ T stage } \\
\hline $\mathrm{T} 1$ & 1 \\
\hline $\mathrm{T} 2$ & 7 \\
\hline $\mathrm{T} 3$ & 9 \\
\hline $\mathrm{T} 4$ & 6 \\
\hline \multicolumn{2}{|l|}{$\mathrm{N}$ stage } \\
\hline N0 & 5 \\
\hline N1 & 5 \\
\hline N2 & 9 \\
\hline N3 & 4 \\
\hline \multicolumn{2}{|l|}{ Thoracic stage } \\
\hline I-IIIA & 14 \\
\hline IIIB & 9 \\
\hline
\end{tabular}

cology care provider for the region where no private pulmonology or oncology services are available. These facts and the structure of the Norwegian health care system allow for evaluation of unselected patient groups almost comparable to large population-based registries, albeit with a limited size. We used the electronic databases of the Departments of Oncology and Palliative Medicine, Pulmonology, and Thoracic Surgery and the Division of Internal Medicine of the NHT to identify all patients treated for histologically confirmed NSCLC between 2006 and 2012 and selected those with stage IV disease at the initial diagnosis, irrespectively of the treatment approach unless no active treatment was given $(n=113)$. All medical records including death certificates and demographic data were available in the hospital's electronic patient record sys- 
Table 2. Treatment details

\begin{tabular}{|c|c|c|c|}
\hline \multirow[t]{2}{*}{ Parameter } & \multirow{2}{*}{$\begin{array}{l}\text { No oligometastases } \\
(\mathrm{n}=90)\end{array}$} & \multicolumn{2}{|l|}{ Oligometastases } \\
\hline & & $\begin{array}{l}\text { Radical or at least moderately } \\
\text { intense treatment }(n=7)\end{array}$ & $\begin{array}{l}\text { Other treatment } \\
(\mathrm{n}=16)\end{array}$ \\
\hline Received systemic therapy & 83 & 43 & 94 \\
\hline More than one line of systemic therapy & 26 & 0 & 50 \\
\hline Received thoracic radiotherapy ${ }^{\mathrm{a}}$ & 43 & $100^{\mathrm{b}}$ & 69 \\
\hline
\end{tabular}

Values are presented as percentages. ${ }^{\mathrm{a}}$ Irrespective of the dose. ${ }^{\mathrm{b}}$ Including patients treated with surgical resection.

tem and were reviewed starting with the first referral for suspected lung cancer. Clinical and imaging follow-up was performed every 2-3 months or earlier in cases of symptom progression. All patients were Caucasian and covered by the national public insurance system. Their treatment was discussed by a multidisciplinary tumor board which met on a weekly basis. Tumor, node, and metastases (TNM) staging was applied as described by Goldstraw et al. [10]. We defined oligometastatic disease as in the recent study by Griffioen et al. [7], i.e. 1-3 synchronous metastases found in only 1 organ (e.g. up to 3 brain metastases, or uni- or bilateral adrenal gland metastases, or up to 3 contralateral lung metastases, or up to 3 liver metastases). Note that separate tumor nodule(s) in the same lobe as the primary tumor are defined as T3, and that separate tumor nodule(s) in a different ipsilateral lobe are defined as T4. Patients with previous malignancies were not included because radiological staging rather than systematic biopsies of metastases was performed (in such cases, metastases might be caused by NSCLC or the previous malignancy). Radiological staging included computed tomography (CT) scans of the chest, abdomen, pelvis, and head and an isotope bone scan. Supplemental ultrasound, magnetic resonance imaging (MRI), or positron emission tomography (PET) was added as appropriate to define the treatment strategy. For example, if the CT scans already showed multiple brain and multiple liver metastases, no further imaging was ordered because the patient would receive primary systemic treatment and whole-brain radiotherapy in any case. If the initial staging showed amenability to a surgical approach, PET-CT and brain MRI were considered appropriate [11]. Radical or at least moderately aggressive local treatment consisted of surgery, chemoradiation, or radiotherapy at a biological dose equivalent to at least 13 fractions of $3 \mathrm{~Gy}$ [7]. None of our patients received extracranial stereotactic ablative radiotherapy. Radiosurgery for brain metastases was available.

\section{Statistical Analysis}

The IBM SPSS Statistics 21 software package (IBM SPSS Statistics, Somers, N.Y., USA) was used for the database and statistical analyses. Actuarial survival from the initial imaging diagnosis was analyzed according to the Kaplan-Meier method. Survival curves were compared using a log-rank test. Only 2 patients were alive at the time of analysis (follow-up: 15 and 17 months, respectively). Initially, we had planned multivariate survival analyses (Cox regression). However, the final number of patients with oligometastases was not sufficient. The following variables were analyzed univariately: age, sex, weight loss, comorbidity, smoking status, $\mathrm{T}$ stage, $\mathrm{N}$ stage, TNM stage (7th edition), initial pattern of metastatic disease, histology, initial management strategy, number of lines of systemic treatment, and use of thoracic radiotherapy.

\section{Results}

The initial study population consisted of 113 patients with stage IV disease who received active therapy; of these, 23 (20\%) had oligometastatic spread (a maximum of 3 metastases to 1 organ). Seven of the 23 oligometastatic-spread cases involved the brain, 7 the adrenal gland(s), 5 the contralateral lung, 3 the skeleton, and 1 the liver. The median age was 71 years (range 56-81). Four patients had an excellent performance status (ECOG 0); 10 were categorized as ECOG 1, and the remaining 9 were ECOG 2. Nineteen patients were males and 4 were females. No mutation was detected in the routine assessment of epidermal growth factor receptor mutations. The baseline characteristics of the patients are given in table 1 . The majority of the patients $(\mathrm{n}=16 ; 70 \%)$ did not receive radical or at least moderately aggressive local treatment at their $\mathrm{T}$ and $\mathrm{N}$ sites (table 2). The details regarding all 7 patients who received such treatment are given in table 3. Most of these patients had brain metastases and a limited thoracic disease extent. Squamous cell carcinoma was slightly overrepresented. All 7 patients developed disease progression during follow-up.

Of the 23 cases, 5 (22\%) were not given systemic treatment because 3 of them were of an advanced age and had comorbidities and the others chose not to receive such treatment. Ten patients received 1 line of systemic treatment ( 2 lines, $\mathrm{n}=5 ; 3$ lines, $\mathrm{n}=2$, and unknown number, $\mathrm{n}=1$ ). Seven patients never received thoracic radiotherapy. The median actuarial survival was 11.7 months (all 23 patients), which was significantly better than the survival of patients with more advanced metastases (median 5.6 months, 1 -year rate $21 \%, p=0.03$ ). Significant differ- 
Table 3. Details regarding patients who received radical or at least moderately intense local treatment of the primary tumor and the involved regional lymphatics $(n=7)$

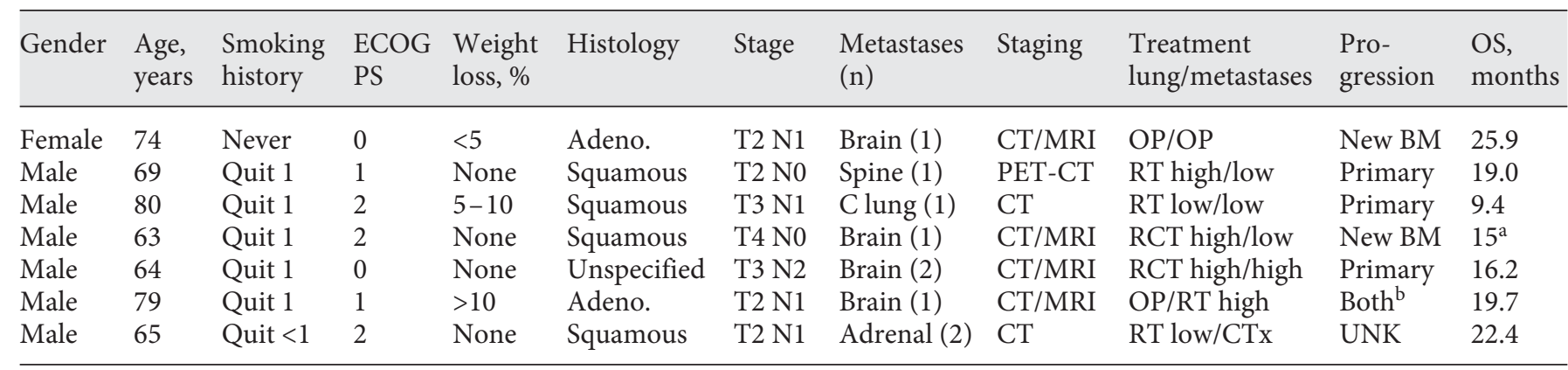

Quit 1 = Quit at least 1 year before the diagnosis; Quit $<1=$ quit less than 1 year before the diagnosis; PS = performance status; OS = overall survival; $\mathrm{RT}=$ radiotherapy; low = biologically equivalent dose of less than $60 \mathrm{~Gy}$ in 2 -Gy fractions, $\alpha$-/ $\beta$-value $10 \mathrm{~Gy}$; high $=$ at least $60 \mathrm{~Gy}$ in $2-\mathrm{Gy}$ fractions (includes brain radiosurgery);
$\mathrm{RCT}=$ concomitant chemo- and radiotherapy; $\mathrm{OP}=$ surgical resection; $\mathrm{C}=$ contralateral; $\mathrm{BM}=$ brain metastases; $\mathrm{CTx}=$ platinumbased doublet chemotherapy; UNK = unknown pattern of progression; Adeno. $=$ adenocarcinoma. ${ }^{\mathrm{a}}$ Alive at the last follow-up. ${ }^{\mathrm{b}}$ Developed new brain metastases and later also mediastinal relapse.

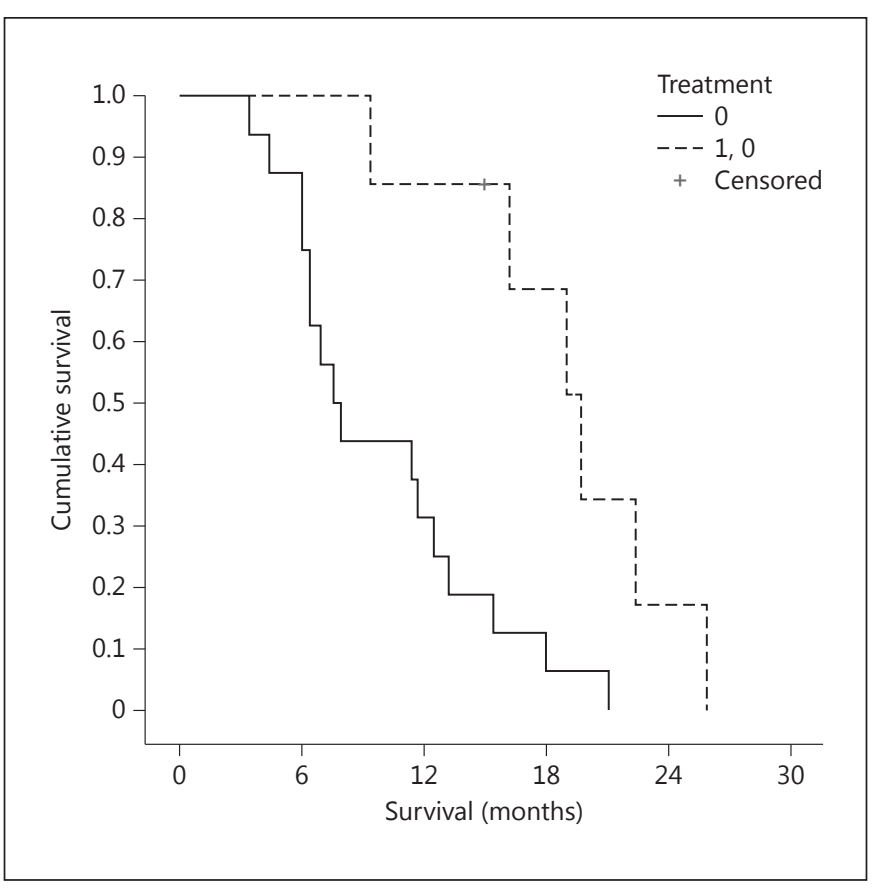

Fig. 1. Actuarial survival of the 2 oligometastatic patient groups with (labeled 1) and without (labeled 0) radical or at least moderately aggressive thoracic treatment (median 19.7 vs. 7.6 months, $\mathrm{p}=0.004$, log-rank test).

ences were seen between the 2 oligometastatic patient groups with and without radical or at least moderately aggressive thoracic treatment (median 19.7 vs. 7.6 months, $\mathrm{p}=0.004$; fig. 1 ). The 1-year survival rate was $86 \% \mathrm{com}$ pared to $25 \%$. Further significant predictors of survival were $\mathrm{N}$ stage $(\mathrm{p}=0.028)$ and weight loss $(\mathrm{p}=0.045)$. Trends were seen for $\mathrm{T}$ stage $(\mathrm{p}=0.058)$ and performance status $(\mathrm{p}=0.07)$.

\section{Discussion}

In our general practice, a clinically significant proportion of patients with NSCLC had oligometastatic disease (20\% had 1-3 metastases limited to 1 site), and this disease state appeared to be associated with better survival. The common sites of oligometastases were the brain and adrenal glands, i.e. mainly sites that are accessible for surgery or stereotactic ablative radiotherapy. The majority of patients had thoracic stage I-IIIA disease, and hence they were eligible for aggressive local treatment as long as their general condition, organ function, and comorbidity allowed for such therapy. These findings suggest that thoracic surgery or (chemo)radiotherapy should be considered using a minimum radiation dose equivalent to at least 39 Gy in 3-Gy fractions that could provide meaningful local control, although most patients received more intense treatment. Despite survival improvement after such treatment, thoracic failure was common.

Our study is different from previous studies in terms of aspects such as practice setting and the use of radical treatment approaches $[7-9,12]$. Some studies also included more patients, i.e. up to 78 . No consistent prognostic factors were identified. In the study by Griffioen et al. [7], 61 patients from 2 centers were treated with radical intent at all sites of disease, unlike our study where inconsistent 
management approaches were used. The median survival rate of 11.7 months in the study by Griffioen et al. [7] was comparable to the 13.3 months in our study, in which not all patients had radical treatment. However, patients with a resected primary or a small radiotherapy target volume had better survival. The 1 -year survival rate of $54 \%$ in our study was slightly lower than the $62 \%$ reported by LopezGuerra et al. [9], who reported on 78 patients, all treated with definitive chemoradiation ( $\geq 45 \mathrm{~Gy}$ ) to the primary site, 44 of whom also had definitive local treatment for the metastases. Performance status, a higher radiation dose, and a smaller thoracic gross tumor volume predicted improved survival. Hasselle et al. [13] treated 25 patients with 5 or fewer metastases with hypofractionated imageguided radiotherapy directed at all sites of active disease. The median survival was 22.7 months, while the progression-free survival was only 7.6 months. Patients who had more than 2 sites treated had a shorter progression-free survival. Local control of the irradiated sites was much better than distant control (66\% compared to $32 \%$ at 18 months of follow-up). An earlier series by Khan et al. [14] included 23 patients with 1-2 metastases treated with chemotherapy and curative local-regional treatment. The median survival was 20 months, as in the series of 38 patients reported by Cheruvu et al. [15]. The latter study included patients with more advanced disease (up to 8 metastases) treated with stereotactic radiotherapy. A prospective phase II trial was reported from the MAASTRO clinic, The Netherlands [8]. It included 40 patients with less than 5 metastases who were eligible for surgery or radical radiotherapy. The majority had local stage III disease and brain metastases ( $87 \%$ had a single metastasis). The median survival was 13.5 months. No prognostic factors could be identified. The median survival in all of the studies discussed here was longer than in our study and varied between 13.5 and 22.7 months. In their systematic review,
Ashworth et al. [6] included 2,176 patients from 49 studies. Of these, $60 \%$ included patients with brain metastases only. Patients with synchronous and metachronous presentations were eligible. The median overall survival was 14.8 months. Significant prognostic factors were: definitive treatment of the primary tumor, $\mathrm{N}$ stage, and a disease-free interval of at least 6-12 months. As correctly stated by the authors, the treatment of oligometastatic NSCLC is based on low levels of evidence and therefore randomized controlled trials are needed. Given that the median survival is still limited to less than 2 years and distant control is difficult to achieve, integration of innovative approaches appears necessary [16].

The limitations of our study include the selection of one particular definition for oligometastatic NSCLC from the existing literature, the retrospective nature of the study, the inclusion of PET-CT only if the results would have impacted management, and the variable treatment approaches used. Furthermore, the final study sample was small. The latter fact hampered subgroup and multivariate analyses. A large population-based study of data from the Cancer Registry of Norway (www.kreftregisteret.no) would have been of interest; however, this database does not contain data on the number of metastases or treatment intensity.

\section{Conclusion}

Our data confirmed the clinical significance of oligometastatic NSCLC in a different practice setting as well as the median survival results reported by larger centers. Defining the most suitable treatment approach (surgery, stereotactic ablative radiotherapy, or chemoradiation) requires systematic research efforts including randomized trials based on standardized staging.

\section{References}

1 Villaruz LC, Kubicek GJ, Socinski MA: Management of non-small cell lung cancer with oligometastasis. Curr Oncol Rep 2012;14: 333-341.

-2 Hanagiri T, Takenaka M, Oka S, et al: Results of a surgical resection for patients with stage IV non-small-cell lung cancer. Clin Lung Cancer 2012;13:220-224.

3 Maclean J, Fersht N, Singhera M, et al: Multidisciplinary management for patients with oligometastases to the brain: results of a 5 year cohort study. Radiat Oncol 2013;8:156.
4 Villarreal-Garza C, de la Mata D, Zavala DG, et al: Aggressive treatment of primary tumor in patients with non-small-cell lung cancer and exclusively brain metastases. Clin Lung Cancer 2013;14:6-13.

5 Torre M, Barbieri B, Bera E, et al: Surgical therapy in lung cancer with single brain metastasis. Eur J Cardiothorac Surg 1988;2:336339.

6 Ashworth A, Rodrigues G, Boldt G, et al: Is there an oligometastatic state in non-small cell lung cancer? A systematic review of the literature. Lung Cancer 2013;82:197-203.
7 Griffioen GH, Toguri D, Dahele M, et al: Radical treatment of synchronous oligometastatic non-small cell lung carcinoma (NSCLC): patient outcomes and prognostic factors. Lung Cancer 2013;82:95-102.

8 De Ruysscher D, Wanders R, van Baardwijk A, et al: Radical treatment of non-small-cell lung cancer patients with synchronous oligometastases: long-term results of a prospective phase II trial (Nct01282450). J Thorac Oncol 2012;7:1547-1555. 
9 Lopez Guerra JL, Gomez D, Zhuang Y, et al: Prognostic impact of radiation therapy to the primary tumor in patients with non-small cell lung cancer and oligometastasis at diagnosis. Int J Radiat Oncol Biol Phys 2012;84:e61-e67.

10 Goldstraw P, Crowley J, Chansky K, et al; International Association for the Study of Lung Cancer International Staging Committee; Participating Institutions: The IASLC Lung Cancer Staging Project: proposals for the revision of the TNM stage groupings in the forthcoming (seventh) edition of the TNM Classification of Malignant Tumours. J Thorac Oncol 2007;2:706-714.
11 Pauwels EK, Coumou AW, Kostkiewicz M, et al: $\left[{ }^{18} \mathrm{~F}\right]$ fluoro-2-deoxy-D-glucose positron emission tomography/computed tomography imaging in oncology: initial staging and evaluation of cancer therapy. Med Princ Pract 2013;22:427-437.

12 De Pas TM, de Braud F, Catalano G, et al: Oligometastatic non-small cell lung cancer: a multidisciplinary approach in the positron emission tomographic scan era. Ann Thorac Surg 2007;83:231-234.

13 Hasselle MD, Haraf DJ, Rusthoven KE, et al: Hypofractionated image-guided radiation therapy for patients with limited volume metastatic non-small cell lung cancer. J Thorac Oncol 2012;7:376-381.
4 Khan AJ, Mehta PS, Zusag TW, et al: Long term disease-free survival resulting from combined modality management of patients presenting with oligometastatic, non-small cell lung carcinoma (NSCLC). Radiother Oncol 2006;81:163-167.

15 Cheruvu P, Metcalfe SK, Metcalfe J, et al: Comparison of outcomes in patients with stage III versus limited stage IV non-small cell lung cancer. Radiat Oncol 2011;6:80.

16 Li Y, Ahmad A, Kong D, et al: Targeting microRNAs for personalized cancer therapy. Med Princ Pract 2013;22:415-417. 